\title{
Paradoxos da (in)visibilidade na migração LGBTIQ+
}

ISSN: $2358-0844$

ก. 12, v.1 поv.2019-abr.2020 p. $143-158$.

\author{
Hadriel Theodoro ${ }^{1}$
}

RESUMO: O objetivo deste artigo é estabelecer um conjunto de reflexões teóricas a respeito dos regimes de (in)visibilidade na/da migração de lésbicas, gays, bissexuais, travestis, transexuais, transgêneras, intersexo, queer e outras minorias sexuais e/ou de gênero (LGBTIQ+). A partir de uma perspectiva transdisciplinar, discute-se a hegemonia das visualidades na contemporaneidade, as dinâmicas constitutivas das políticas de visibilidade e suas implicações nas experiências de vida de imigrantes e refugiadas/os LGBTIQ+.

PALAVRAS-CHAVE: Migração LGBTIQ+. Refúgio LGBTIQ+. Políticas de visibilidade. Comunicação. Mídia.

\begin{abstract}
This paper reflects on the (in)visibility regimes in the/of the migration of lesbian, gay, bisexual, transvestite, transexual, trangender, intersex and queer subjects (LGBTIQ+). Based on a transdisciplinary perspective, we discuss the hegemony of visualities in contemporary society, the constitutive dynamics of visibility policies and their implications in the life experiences of LGBTIQ+ immigrants and refugees.

Keywords: LGBTIQ+ migration. LGBTIQ+ refuge. Visibility policies. Communication. Media.

Resumén: Este artículo tuvo como objetivo establecer un conjunto de reflexiones teóricas sobre los regímenes de (in)visibilidad en/de la migración de lesbianas, gays, bisexuales, travestis, transexuales, transgéneras, intersexo, queer y otras minorías sexuales y/o de género (LGBTIQ+). Desde una perspectiva transdisciplinaria, discutimos la hegemonía de las visualidades en los tiempos contemporáneos, las dinámicas constitutivas de las políticas de visibilidad y sus implicaciones en las experiencias de vida de inmigrantes y refugiadas/os LGBTIQ+.

Palabras clave: Migración LGBTIQ+. Refugio LGBTIQ+. Políticas de visibilidad. Comunicación. Medios de comunicación.
\end{abstract} ${ }^{1}$ Mestre em Comunicação e Práticas de Consumo pela Escola Superior de Propaganda e Marketing (ESPM-SP) e
doutorando na mesma instituição (bolsista pela Fundação de amparo à Pesquisa do Estado de São Paulo - Fapesp).
Graduado em Comunicação Social pela Escola de Comunicações e Artes da Universidade de São Paulo (ECA-USP) e em
Letras pela Faculdade de Filosofia, Letras e Ciências Humanas (FFLCH-USP). E-mail: hgtheodoro@gmail.com 


\section{Introdução}

Desde a etapa de formulação do projeto que deu início ao desenvolvimento da minha pesquisa de doutorado sobre imigração e refúgio de pessoas lésbicas, gays, bissexuais, travestis, transexuais, transgêneras, intersexo, queer e outras minorias sexuais e/ou de gênero $(\text { LGBTIQ+ })^{2}$, a escassez de informações sobre o tema me trouxe uma série de questionamentos práticos: quem são esses sujeitos? Onde encontrá-los? Como estabelecer um primeiro contato? De que forma acessar suas experiências de vida? Logo percebi que estava diante de uma problemática: o apagamento de sua existência.

Por mais que já tivesse realizado uma pesquisa sobre as dinâmicas e políticas de (in)visibilidade para sujeitos LGBTIQ+, sobretudo no âmbito midiático (THEODORO, 2017), no caso de sujeitos LGBTIQ+ migrantes o desafio estava, antes de tudo, no campo. Sua invisibilidade em diferentes instâncias (social, cultural, política, jurídica, educacional, midiática etc.) se mostrou uma grande barreira a ser transposta. Como poderia me propor a estudar as experiências de vida desses sujeitos sem conhecê-los? E como conhecer uma realidade que não se pode ver?

Se, por um lado, tal complexidade apontava para a dificuldade de levar a cabo o estudo proposto, por outro, assinalava uma de suas justificativas fundamentais: o fato de ser imprescindível a visibilização acerca do assunto. Por isso apresento neste artigo um conjunto de reflexões teóricas que considero relevantes para problematizar os regimes de (in)visibilidade e suas implicações nas vivências de sujeitos LGBTIQ+ migrantes. Partindo do campo da comunicação social, proponho considerar, desde uma perspectiva transdisciplinar, o domínio do visual em nossa vida cotidiana, as políticas de visibilidade e as especificidades da migração LGBTIQ+.

\section{Do império das visualidades às políticas de visibilidade}

Na perspectiva teórico-conceitual da configuração de uma "pós-modernidade", Harvey (1992) aponta como uma das características substanciais de diferenciação do período histórico que vivenciamos a contínua compressão espaço-temporal. Por meio de uma série de (r)evoluções

${ }^{2}$ Em andamento desde fevereiro de 2017 no Programa de Pós-Graduação em Comunicação e Práticas de Consumo da Escola Superior de Propaganda e Marketing de São Paulo (PPGCOM-ESPM), tem por objetivo principal analisar como a visibilidade ou invisibilidade da diferença ontológica em relação a uma identidade de gênero e/ou orientação sexual não hegemônica impacta as experiências migratórias de sujeitos LGBTQI+ que vivem na cidade de São Paulo (Brasil) ou Barcelona (Espanha). O estudo conta com financiamento da Fapesp (processos 2016/24566-1 e 2018/18712-0).

Periódicus, Salvador, n. 12, v.1, nov.2019-abr.2020 - Revista de estudos indisciplinares em gêneros e sexualidades Publicação periódica vinculada ao Núcleo de Pesquisa NuCuS, da Universidade Federal da Bahia - UFBA ISSN: 2358-0844 - Endereço: http://www.portalseer.ufba.br/index.php/revistaperiodicus 
técnicas e tecnológicas que reordenam o funcionamento do mercado, abre-se caminho para novas lógicas de consumo. Acumulação flexível, curso indireto de produção, financeirização e desmaterialização do capital, efemeridade, descartabilidade e ruptura da fixidez de fronteiras são apenas algumas das consequências desse processo, cujo espraiamento é rizomático e global. Nesse sentido, há de se salientar que tal compressão impacta diretamente tanto as práticas políticoeconômicas quanto a vida social e cultural, atingindo - em maior ou menor grau - inclusive a dimensão do sujeito, concernente aos modos de pensar, sentir e agir. (HARVEY, 1992)

Outro elemento que não pode ser desconsiderado é a comunicação, sobretudo aquela mediada por aparatos tecnológicos. Isso porque a maneira como nos inter-relacionamos cotidianamente reflete e refrata as metamorfoses espaço-temporais: por um lado, os avanços nas tecnologias da informação e da comunicação (TICs) contribuem para que estejamos cada vez mais próximos e, ao mesmo tempo, para que sejamos capazes de nos fragmentar em múltiplos espaços, em deslocamentos transfronteiriços; por outro, essas mesmas tecnologias servem à aceleração do giro de capitais em escala mundial, o que retroalimenta a perpetuidade do sistema capitalista. No que se refere ao âmbito microssocial, as comunicabilidades tecnologicamente mediadas adquirem uma relevância ainda mais expressiva. Gostaria de me deter brevemente em seus impactos à questão das visualidades, imprescindível às ponderações que aqui proponho efetuar. Com esta finalidade, penso que poderíamos retomar o advento da fotografia como ponto de partida à empreitada.

Mediante um conjunto de avanços técnicos, desenvolvidos fundamentalmente ao longo do século XIX, a fotografia passa a reconfigurar as relações entre sujeito-imagem e sujeitorealidade. $\mathrm{O}$ registro visual do mundo por ela facultado representa um recorte de determinado espaço-tempo, se estruturando como uma extensão da realidade, preservada em uma materialidade tecnomidiática. Assim, obtém status de verdade e de suporte de uma memória (individual e coletiva) expandida (BAITELLO, 2010) - talvez de onde provenha a máxima de que "uma imagem vale mais que mil palavras". Conforme explicita Crary (2012), ocorre nesse processo até mesmo uma modificação sistêmica do olhar, devido à necessidade de adaptação a um novo domínio simbólico - o que conduz, em uma vertente benjaminiana, a um "novo sensorium".

Com o cinema, tal domínio será extremamente ampliado, uma vez que as imagens ganham movimento e passam a retratar não apenas fragmentos do mundo, mas, sim, um fluxo: um continuum capaz de espelhar o "real" e dar asas ao onírico. Não é de se estranhar, portanto, 
que, quando das primeiras exibições cinematográficas produzidas pelos irmãos Lumière, as/os espectadoras/es saíssem correndo da frente da tela, com medo de serem atropeladas/os por um trem que chegava à estação. Trata-se de um caso exemplar no que diz respeito à potência simbólica das visualidades, posto que a imagem do trem em movimento não passa de uma representação do trem em movimento, capturada em data e local específicos, a partir de determinados métodos e respeitando limitações da própria técnica (como a ausência de cor e áudio). Mas isso pouco importa no momento da recepção, pois, projetado na tela branca e contrastando com um ambiente lúgubre, o trem-imagem ressurge como extensão do trem-real, cujo deslocamento se difunde no espaço-tempo até alcançar a retina de quem assiste à exibição, despertando efeitos físicos e emocionais irrefutáveis.

Anos mais tarde, a televisão, em sua hibridação midiática, levaria essas imagens em movimento para a esfera privada. Após sua popularização, passam a se arraigar à vida cotidiana, estando já profundamente vinculadas à propaganda. Pode-se notar, nesse sentido, que diferentes dinâmicas de consumo se concatenam: o consumo do bem (televisão) estimula um consumo midiático cujo sustentáculo está fortemente apoiado no modus operandi do mercado (de bens e serviços), que responde, por sua vez, ao paradigma do imagético. Logo, consumo, mídia e visualidade não se dissociam; ao contrário, emergem como um amálgama a partir do qual hábitos, valores e subjetividades são fomentados.

Não podemos deixar de levar em conta que na contemporaneidade ocorre uma aceleração exponencial das transformações nas TICs, especialmente com a disseminação da internet e com o incremento da interatividade proporcionada pela web $2.0^{3}$. De maneira inegável, vivemos hoje em uma sociedade midiatizada e nossa jornada diária é (indireta ou diretamente) mediada pelas mídias, que (re)definem em permanência o modo de experienciar a realidade. Em suas ambiências digitais, na fluidez da hipermídia, o império das visualidades avança.

O que busco evidenciar com essa explanação é o fato de que, no que concerne à organicidade da semiosfera em que nos inserimos, a concretude simbólica das imagens e das imagens da/na mídia se transmutam em um elemento basilar às práticas sociais. (BAITELLO, 2010; HARVEY, 1992) Produzimos imagens, as intercambiamos incessantemente, as consumimos: habitamos nas imagens e elas habitam em nós. Da fotografia ao cinema, da televisão à web, os fluxos imagéticos na contemporaneidade são um dos principais indicadores

\footnotetext{
3 Termo cunhado por Tim O’Reilly, que corresponde à transformação da web em plataforma, permitindo maior interação entre seus/suas usuários/as, bem como a produção e compartilhamento de conteúdo e informação. 
da compressão espaço-temporal a que Harvey (1992) faz alusão. Isso porque, no curso de uma comunicação em rede, transmidiática e global, colocam o sujeito em contato constante com o ontem-agora-amanhã, o "lá”, o Outro, a diferença.

As (audio)visualidades atuam na constituição de representações sociais, por intermédio de contratos de visibilidade que englobam o sujeito, os meios de comunicação e seus níveis de institucionalidade. (MACHADO, 2001) Com a conformação de uma mídia cada vez mais policêntrica, as imagens passam, por meio de práticas de produção-circulação-consumo, a se impregnar em formas de identificação e identidade, uma vez que mediam as relações sociais e as disputas simbólicas aí abarcadas. (ROCHA, 2017)

Especificamente em relação à temática das migrações, é importante destacar os impactos concretos que a profusão dos fluxos imagéticos acarreta às (des)construções de representações sobre e de quem migra e acerca dos locais de origem e de destino, (re)modelando um imaginário coletivo a respeito do Outro-migrante. Muitas vezes, todavia, essas visualidades contribuem para a manutenção de estereótipos.

Um exemplo é a foto de Aylan Kurdi, uma criança síria de três anos de idade morta afogada quando tentava, com várias/os imigrantes, atravessar o mar Egeu em um bote para chegar à Grécia, em 2015. A imagem do corpo de Aylan, já sem vida, inerte na areia da praia em Bodrum (Turquia), adquiriu grande repercussão midiática e foi veiculada por dias a fio em diferentes tipos de mídia, como um reflexo da "crise migratória". O problema em si não reside propriamente naquilo que a imagem expõe nem em toda sua potencialidade para chocar ou comover. O que acaba por "esvaziá-la" de sentido é sua entrada em um império de visualidades em que a reprodutibilidade se processa à exaustão e as engrenagens da produção-consumo nunca deixam de girar.

Por outro lado, a imagem oculta ao "revelar", ou seja, ela mostra apenas uma criança morta. A mãe e o irmão de Aylan tiveram o mesmo fim trágico, além de, pelo menos, outras dez pessoas. A organização não governamental Save The Children, por exemplo, reportou em 2018 que, desde a morte de Aylan, ao menos outras 640 crianças morreram afogadas no mar Mediterrâneo tentando chegar à Europa ${ }^{4}$. Inúmeras/os imigrantes morrem diariamente nas mesmas circunstâncias. E seus corpos? E suas vidas? A mobilização pautada nos compartilhamentos e consumos da imagem de Aylan em espaços midiáticos como forma de

${ }^{4}$ Disponível em: http://bit.ly/2IT8E00. Acesso em: 10 jul. 2019.

Periódicus, Salvador, n. 12, v.1, nov.2019-abr.2020 - Revista de estudos indisciplinares em gêneros e sexualidades Publicação periódica vinculada ao Núcleo de Pesquisa NuCuS, da Universidade Federal da Bahia - UFBA ISSN: 2358-0844 - Endereço: http://www.portalseer.ufba.br/index.php/revistaperiodicus 
denúncia e sensibilização para sua morte pode não ter contribuído, como se desejava ou se imaginava, para cessar as mortes de imigrantes e refugiadas/os e nem promover uma melhoria significativa nas políticas de acolhida em países europeus. Além disso, não se pode negligenciar a apropriação dessas imagens por veículos de imprensa, por empresas de mídia que lucram com elas, sem contar todo o dilema ético que pode ser levantado e trazido como pano de fundo à discussão.

Ainda em 2015, mas na cidade de São Paulo, outra foto ficou bastante conhecida ao ser divulgada pela imprensa (originalmente nos jornais Agora e Folha de São Paulo) e replicada incontáveis vezes na internet. Trata-se de um imigrante haitiano que "se banha" no mictório de um dos banheiros da Missão Paz, que gerencia a Casa do Migrante e é reconhecida como um dos principais centros de acolhida a imigrantes e refugiadas/os no país.

A imagem (obtida sem o consentimento do imigrante nela retratado), que posteriormente inclusive ganhou o Prêmio Vladimir Herzog de Anistia e Direitos Humanos, expõe de modo muito patente como a problemática é complexa e deve ser encarada com cuidado, uma vez que a publicização dessas imagéticas do Outro-migrante reverberam questões de direitos humanos, cidadania, apropriação, exploração da precariedade, capacidade de agência etc. Em uma análise sobre a referida imagem, Cogo e Pássaro (2017, p. 4) reportam que ela não é um caso isolado e que os embates gerados em torno de sua publicação são reveladores de alguns "dilemas relacionados aos imbricamentos entre estética e política que demarcam os novos regimes de visualidade da sociedade contemporânea, os quais têm tido incidência nos processos de visibilidade midiática das chamadas minorias [...]”.

Essas visualidades do Outro-migrante (re)desenham em permanência os fluxos imagéticos das migrações - sempre se ressignificando no âmbito do consumo e da recepção. Logo, o entendimento das intersecções entre capital, mídia e visualidades é muito importante para problematizar a questão da visibilidade, dado que as imagens, para além de portadoras de sentido, contêm um caráter eminentemente político.

Por mais que estejamos imersos no império das visualidades, é necessário ter em mente que nem toda imagem consegue lograr um status de legibilidade sociocultural - que configura (ou não) a propriedade de sua visibilidade. (ROCHA, 2009) Então algumas perguntas advêm indispensáveis (ROCHA, 2017): para onde olhar? Com que olhos? O que realmente somos capazes de ver? O que e quem pode de fato ser visto? 
Na conjuntura contemporânea, o binômio da escassez-excesso é bastante explicativo da condição paradoxal que regula o funcionamento da lógica capitalista, incluindo sua 'tecnomegaesfera' imagética. Se a produção-circulação-consumo de imagens cresce progressivamente, impulsionada pela disseminação dos usos e apropriações das TICs, por outro lado, diversos atores e grupos sociais, causas e desigualdades estruturais carecem de visibilidade pública - como é o caso de sujeitos LGBTIQ+, sobretudo migrantes.

Devemos ponderar, por conseguinte, que tanto as visualidades quanto as visibilidades estão inscritas em práticas de consumo que respondem à atual lógica capitalista. Para muito além de seu viés utilitarista ou do senso comum, que o toma como "supérfluo", o consumo gera, comunica e transforma sentidos socioculturais compartilhados - que, por sua vez, estão constantemente em trânsito -, sendo "parte da racionalidade integrativa e comunicativa" da sociedade. (GARCÍA CANCLINI, 1999, p. 80) Negociações e embates não deixam de estar presentes no fluxo das significações de onde o status de visibilidade das imagens pode ou não advir. Entre ser ou não ser visível, estabelecem-se verdadeiras lutas por significado, âmbito medular das políticas de visibilidade.

Uma vez que todas as nossas relações sociais estão, indireta ou diretamente, mediadas pelas imagens (BAITELLO, 2010), voltemos à questão “O que e quem pode ser visto?”. Sua simplicidade sintática contrasta profundamente com a intrincada problematização que necessita ser feita a respeito da invisibilidade. Em tempo de grandes fraturas, segmentações, heterogeneidade e comunicações transnacionais fluidificadas (GARCÍA CANCLINI, 1999), poderíamos supor que a invisibilidade não seria em si um problema, já que, com os aparatos técnicos provenientes das TICs, tudo é capaz de se transformar em imagem e adentrar a esfera midiática da produção-circulação-consumo. Mas seríamos ingênuas/os demais se acreditássemos que, pela técnica, uma perfeita igualdade entre partes estaria garantida. Aqui precisamos dar alguns passos atrás e relembrar que a imagem é, antes de mais nada, uma representação da realidade, e, por isso mesmo, nunca poderá ser contida em sua integralidade: sempre há um sujeito, um olhar, uma perspectiva, um modo de tornar visível.

Nesse sentido, toda visibilidade inclui em si alguma forma de invisibilidade, como a relação entre luz e sombra. É por isso que políticas de visibilidade se associam intimamente com o que García Canclini (1999) nomeia de "políticas de representação". Enquanto processo sociocultural partilhado que confere a determinadas imagens a propriedade de partícipe de um 
sistema de legibilidade, a visibilidade abarca impreterivelmente uma característica de relevância social. (ROCHA, 2009) Sua efetividade simbólica fica dependente do grau dessa relevância e da viabilidade de sua legibilidade.

O que é visível, portanto, não necessariamente tem a ver com o que se torna imagem, mas, sim, com o que, ao advir essa visualidade, via lutas por significado e estratégias comunicacionais, passa a ter reconhecido seu valor sociocultural. (ROCHA, 2009) Ou seja, tratase de um "recorte significante particular feito em um todo visual múltiplo e abrangente". (ROCHA, 2009, p. 273) O problema reside no fato de que as visualidades e, consequentemente, as visibilidades, sempre são valoradas de maneira assimétrica.

Além disso, há de se considerar que as lógicas do capitalismo contemporâneo em grande parte são regidas por monopólios empresariais, cuja capilaridade de suas ações, sobretudo por meio de um processo de monetarização e financeirização do capital, se expande pelo globo. (GARCÍA CANCLINI, 1999; HARVEY, 2011) Por mais que as TICs atuais permitam uma descentralização e horizontalização das práticas comunicacionais, isso não significa o fim das institucionalidades que a regem. Grandes conglomerados midiáticos continuam a existir - muitas vezes tendo seus negócios potencializados e expandidos por essas mesmas TICs -, vide 21st Century Fox, CBS, Comcast, Grupo Globo, Televisa, Walt Disney; os tão aclamados sites de rede social, como Facebook, Instagram, LinkedIn, Twitter, dentre outros, são controlados de perto por empresas da área de tecnologia e seus misteriosos algoritmos; idem para grandes sites de busca e compartilhamento de conteúdo midiático, tais como Google Search, Yahoo, YouTube, WhatsApp etc. O resultado da equação é "simples": as visibilidades são engendradas em relação $a$, isto é, mediadas socioculturalmente e atravessadas por institucionalidades múltiplas e seus consequentes interesses e enquadramentos (estéticos, de formato, de discurso).

Logo as mídias, sejam elas hegemônicas ou alternativas, se convertem em uma instância privilegiada para problematizar a questão das políticas de visibilidade, pois permitem verificar os trânsitos entre o visível e o invisível a que as visualidades estão propensas. É pelas mídias que atores e movimentos sociais têm a possibilidade de fundamentar suas ações e estruturá-las de modo a objetivar uma visibilidade pública que, em retroalimentação, pode ao menos legitimar sua existência. Eles se apropriam e (re)compõem essas dinâmicas de visibilidade social, transfigurando o domínio das mídias em um lócus simbólico de conflitos e negociações, ininterruptamente condicionado pelos tensionamentos de interesses sociais os mais diversos. 
As políticas de visibilidade estão, desse modo, entremeadas por um contínuo processo de embates, principalmente no âmbito midiático. Como decorrência, as micropolíticas cotidianas de visibilidade passam a (re)configurar, no processo da constituição de agenda pública, uma miríade de demandas (materiais e/ou simbólicas) - que não deixam de estar subordinadas às práticas de consumo na lógica capitalista contemporânea, uma vez que ele é um "fato cultural e uma manifestação imagética na qual se inclui uma ampla gama de imagens (imaginadas, visuais, olfativas, gustativas, táteis e sonoras)". (ROCHA, 2008, p. 125) Estão colocadas aí as limiaridades e inter-relações das (in)visibilidades enquanto políticas.

\section{Das (in)visibilidades na migração LGBTIQ+}

Para refletir acerca das (in)visibilidades na (e também da) migração de lésbicas, gays, bissexuais, travestis, transexuais, transgêneros, queer e outras minorias sexuais e/ou de gênero, é preciso compreender primeiramente as normatizações que recaem sobre as formas como experienciamos nossos corpos, desejos, identidades de gênero e orientações sexuais. As teorias, estudos e autoras/es que versam a respeito da temática são bastante profícuas/os, permitindo abordagens em diferentes linhas teórico-epistemológicas. Considero a abordagem de Paul B. Preciado bastante válida nesse sentido, haja vista que seu entendimento sobre as vinculações entre sistema socioeconômico e gestão política da vida é significativo à problemática.

Preciado (2008) assevera que é precisamente por meio das novas dinâmicas do tecnocapitalismo avançado que nossas subjetividades passam a ser geridas por dispositivos microprostéticos de controle e plataformas técnicas - biomoleculares e midiáticas. Para o autor, há um regime pós-industrial, global e midiático que intitula 'farmacopornográfico', sendo uma das consequências mais perversas das lógicas do capital na contemporaneidade, referentes aos processos de controle molecular (farmaco) e semiótico (porno) de nossa existência. Como bem sintetiza, "a produção farmacopornográfica caracteriza hoje uma nova era da economia política mundial, não por sua preponderância quantitativa, mas porque o controle, a produção e a intensificação dos afetos narcótico-sexuais se tornaram o modelo de toda uma outra forma de produção". (PRECIADO, 2008, p. 39, tradução minha)

Nesse biocapitalismo contemporâneo, processam-se novas formas de controle dos corpos codificados com base em uma dicotomia do sexo (mulher versus homem), do gênero (feminino versus masculino) e da orientação sexual (não heterossexualidade versus heterossexualidade), $\underline{\text { estritamente arraigada às dinâmicas do capital e às práticas de consumo. Potencializadas pelo }}$ 
midiático, em suas técnicas de visão e difusão de informação, os dispositivos sexopolíticos do regime farmacopornográfico atuam de modo a regimentar a composição estética das diferenças sexuais e de gênero, convertendo-se em técnicas mecânicas, semióticas e arquiteturais de sua naturalização. (PRECIADO, 2008) No seio do regime farmacopornográfico, tanto o desejo quanto o sexo e o gênero se constituem por meio de redes de materialização biopolítica, sendo (re)produzidos e consolidados socialmente por sua transformação em espetáculo, imagens móveis, dados numéricos, moléculas e cibercódigos. (PRECIADO, 2008)

Patenteia-se uma "ecologia somatopolítica reguladora" (PRECIADO, 2008) que regimenta um marco limítrofe entre o normal e o patológico, o padrão e o desvio, a pureza e a poluição, o bio e o tecno. Quanto maior a correspondência com o padrão hegemônico normativo (no que diz respeito à estética, ao desejo, ao gênero, à sexualidade etc.), mais se tornam plausíveis os códigos de visibilidade que asseguram uma legibilidade sociocultural. A julgar que hoje "o poder se estende ao sexo e ao gênero como codificações precisas da informação e da subjetividade" (PRECIADO, 2008, p. 231, tradução minha), não é de se estranhar que a dissidência dessa divisa de normalidade represente a consequente subalternização, vulnerabilização e precarização da existência. É o que ocorre, em maior ou menor intensidade, com todos os sujeitos LGBTIQ+. (WESLING, 2008)

Quando debatemos a respeito das migrações, não é raro que haja uma personificação de quem migra na figura do "homem migrante", difundida no imaginário social - demandando empenho de nossa parte para efetuar uma "correção do olhar" (KRZESLO, 2007), ou seja, não tomar o "migrante" como um sujeito hegemonicamente masculino, heterossexual e cisgênero 5 . Ao contrário, é urgente e de extrema importância considerar a diversidade contida nos fluxos migratórios na contemporaneidade e, ao mesmo tempo, compreender que as formas de vivenciar os desejos, as identidades de gênero e as orientações sexuais produzem impactos profundos nas (des)continuidades da experiência migratória como um todo (e vice-versa).

Em relação às experiências migratórias de sujeitos LGBTIQ+, sempre há uma desestabilização interseccional da normatividade: por um lado, como típico dos deslocamentos humanos, rompe-se com um (pretenso) ordenamento geográfico (local, internacional ou transnacional), em que estão implicados certos arranjos sociais, culturais, econômicos e políticos; por outro, há uma desestabilização dos biocódigos produtores de subjetividade,

${ }^{5}$ Cisgeneridade diz respeito a pessoas que foram designadas com determinado gênero ao nascer e com ele se identificam. 
fundamentados na matriz heterocisnormativa do ser vivente. (PRECIADO, 2008) Aí se encontra a relevância de - na interação interseccional ${ }^{6}$ com outros marcadores sociais de diferença, como origem étnica, raça, classe, idade, religião etc. - reflexionar sobre os desejos, identidades de gênero e orientações sexuais enquanto variáveis a serem analisadas e englobadas nos estudos migratórios.

Ademais, na medida em que o sujeito “desviante" é continuamente destituído da capacidade de ser agente de sua própria representação (PRECIADO, 2008), impelido a um lócus de silenciamento e invisibilidade, produz-se um conjunto de impactos nas dinâmicas de (in)visibilidade engendradas nos fluxos migratórios de sujeitos LGBTIQ+. Tais (in)visibilidades, há de se salientar, condicionam esses sujeitos à precarização e, em concomitância, assinala a viabilidade de uma política de (re)existência, o que é substancial para se debater acerca das experiências de sujeitos LGBTIQ+ migrantes.

Em diversos países, por exemplo, não há garantias cidadãs ou de direitos aos sujeitos LGBTIQ+, que são reduzidos a objeto de abuso e discriminação - uma precarização da vida que inclui insultos, perseguições, prisões arbitrárias, violência sexual, tortura e até mesmo assassinatos 7 . (MOGROVEJO, 2015; WESLING, 2008) Quanto mais visível for a dissidência, isto é, quanto mais se divergir exteriormente de um padrão hegemônico, mais riscos se passa a correr. Em conjunturas socioculturais intensamente repressivas, definidas por abusos oriundos de diferentes instituições (Estado, Igreja, sistema educacional, medicina, complexo jurídico etc.), estimulados por dogmas religiosos, costumes, desinformação, condenações morais, imaginários estereotipados e preconceitos, o deslocamento advém uma possibilidade não somente de maior liberdade, mas, acima de tudo, de sobrevivência. (WESLING, 2008)

No que tange aos deslocamentos internos (no interior do limite do Estado-nação), a migração de áreas rurais a urbanas e de pequenas a grandes cidades foi e continua sendo recorrente a sujeitos cujos desejos afetivo-sexuais e/ou identidades de gênero não se enquadram ao regime disciplinar heterocisnormativo. (ANDRADE, 2017) Em especial, os grandes conglomerados metropolitanos exercem uma forte atratividade a sujeitos LGBITQ+, uma vez que representam uma ambiência (espacial e simbólica) singular à arquitetura de suas subjetividades dissidentes, em razão de uma maior liberdade à expressão de diferenças, uma menor vigilância social e um relativo anonimato. (ANDRADE, 2017)

6 Interseccionalidade corresponde a formas de apreender os efeitos da interação entre duas ou mais formas de precariedade: xenofobia, racismo, sexismo, misoginia, homofobia, lesbofobia, transfobia etc. (cf. HIRATA, 2014)

7 Em mais de 70 países, por exemplo, as relações afetivo-sexuais entre pessoas do mesmo gênero ainda são criminalizadas, podendo resultar inclusive em pena de morte (como na Arábia Saudita, no Irã, no Sudão e no Iêmen). 
Evidentemente não há de se conjecturar que as violências direcionadas a sujeitos LGBTIQ+ deixem de ocorrer nesse meio. No entanto torna-se claro que as referidas características produzem em suas espacialidades (ou circuitos urbanos) um sentimento mais profundo de comunidade e pertencimento, favorecendo uma micropolítica de resistência e de (re)existência - fomentada notadamente por meio de uma visibilidade sociocomunicacional no âmbito público, vale destacar.

Já no que concerne às migrações inter ou transnacionais, é preciso atentar a duas variáveis. A primeira se refere às migrações de caráter voluntário, que podem decorrer de projetos migratórios variados: estudos, trabalho, vínculos familiares, fatores culturais e socioeconômicos etc. Nessa categoria de mobilidade humana, a/o imigrante não se vê rigorosamente compelida/o a deixar seu país de origem. De fato, empreende um projeto migratório abarcando fatores objetivos e subjetivos, materiais e imateriais, ainda que, de modo indireto, a questão da orientação sexual e/ou identidade de gênero também possa estar presente, operando como um princípio decisivo à migração.

A segunda variável é relativa a uma categoria específica de deslocamento humano, que abrange o condicionamento a um status migratório regulamentado: o refúgio. Em 1951, na Convenção Relativa ao Estatuto dos Refugiados, convencionou-se caracterizar a/o refugiada/o como uma pessoa que, "temendo ser perseguida por motivos de raça, religião, nacionalidade, grupo social ou opiniões políticas, encontra-se fora do país de sua nacionalidade e que não pode, ou em virtude desse temor, não quer valer-se da proteção desse país”. (ORGANIZAÇÃO DAS NAÇÕES UNIDAS, 1951, p. 2) No ano de 1967, com o Protocolo sobre o Estatuto dos Refugiados, esses critérios passaram a valer mais amplamente no quadro do direito internacional para a aceitabilidade dos pedidos de refúgio. Todavia em nenhum dos documentos a orientação sexual ou a identidade de gênero estão explicitamente elencadas como razões pertinentes à solicitação e à concessão do status de refugiada/o. (NASCIMENTO, 2018)

Por conta da polissemia que encerra, o critério "grupo social" passou ao longo do tempo a acolher pedidos de refúgio de migrantes que não se enquadravam nos outros quatro, como no caso de mulheres que sofrem violência de gênero em sua sociedade de origem e, posteriormente, sujeitos LGBTIQ+. O primeiro requerimento desse tipo foi deferido na Holanda, ainda na década 
de 1980. (NASCIMENTO, 2018) Desde então, alguns países ${ }^{8}$ começaram a aceitar que sujeitos LGBTIQ+ sejam integrados na categoria "grupo social", posto que a intolerância, os preconceitos e as violências simbólicas e/ou físicas com que lidam cotidianamente no país de origem são compreendidos como elementos válidos à solicitação de refúgio.

Contudo, não existindo uma especificação legal que assegure a proteção integral às/aos refugiadas/os LGBTIQ+, a aceitabilidade da solicitação do refúgio e sua outorga ficam subjugadas a um entendimento subjetivo por parte do corpo jurídico do Estado-nação de destino. Nascimento (2018) destaca que nos Estados Unidos, por exemplo, muitas vezes é preciso que a/o solicitante de refúgio LGBTIQ+ comprove que possui (ou possuía) visibilidade social individualizada de sua orientação sexual e/ou identidade de gênero. Desconsiderando o critério de "grupo social", nesse caso não basta ser LGBTIQ+, tem de parecer LGBTIQ+, ou seja, externar características de legibilidade que evidenciem uma (estereotipia de) orientação sexual e/ou identidade de gênero não hegemônicas, o que passa pela visibilização da subjetividade em códigos preconcebidos e formatados de acordo com o reverso do padrão da "normalidade". Como podemos verificar, esse processo é extremamente complicado e subordinado a uma miríade de "aprovações" institucionais no país de destino, passando rigorosamente tanto pela fundamentação do temor de perseguição quanto pela comprovação (muitas vezes visual) de determinada orientação sexual e/ou identidade de gênero.

Essa conjuntura nos permite verificar como as (in)visibilidades das/nas experiências migratórias de sujeitos LGBTIQ+ têm relevância tão significativa. Isso porque é no jogo entre o vir a ser visível ou permanecer invisível que se processam possibilidades de resistência ou de (re)existência, individual ou coletivamente. É por esse motivo que as políticas de visibilidade para/de sujeitos LGBTIQ+ migrantes apresenta uma grande complexidade.

Novamente estamos diante de um paradoxo da (in)visibilidade: se, por um lado, há a necessidade de visibilização no espaço público, por meio da qual se propicia o estabelecimento de lutas por reconhecimento, demandas por cidadania, agência política e embates por transformações socioculturais, por outro, essa mesma visibilização se transmuta em uma vertente de vulnerabilidades, uma vez que se ancorar em tal visibilidade equivale a reafirmar as diferenças de caráter ontológico que sustentam as assimetrias e desigualdades a que estão impostos.

${ }^{8}$ Tais como Alemanha, Argentina, Brasil, Bélgica, Canadá, Dinamarca, Espanha, Estados Unidos, Holanda, Reino Unido e Suécia. 
$\mathrm{Na}$ medida em que estamos imbuídas/os em um ordenamento heterocisnormativo de corpos, desejos e subjetividades, regulado e corroborado pela lógica farmacopornográfica do capital (PRECIADO, 2008), o mero fato de aparentar qualquer forma de dissidência a sua hegemonia representa a suscetibilidade a violências múltiplas. É muito comum, por exemplo, imigrantes e, mais particularmente, refugiadas/os LGBTIQ+ temerem visibilizar sua orientação sexual e/ou identidade de gênero por conta da comunidade de compatriotas na sociedade de destino, pois ela normalmente replica o quadro discriminatório da localidade de onde provêm; ou também pelo fato de continuar a haver nessa sociedade de destino um ambiente fóbico a sujeitos LGBTIQ+. (ANDRADE, 2017; THEODORO; COGO, 2018) A isso se agrega ainda a experiência da clandestinidade, que é intrínseca à migração, já que muitos migrantes que não dispõem de regularização jurídica podem temer uma visibilidade pública também por este motivo. (THEODORO; COGO, 2018)

Todos esses âmbitos estão entremeados pelos usos, mediações e apropriações de TICs, que vão (des)construindo representações sobre e de migrantes, sempre mediadas por embates em torno da produção de sentido. Em um estudo sobre a representação de sujeitos LGBTIQ+ em portais de notícia brasileiros, pude verificar, por exemplo, a tendência à estereotipia, que limita a apreensão das complexas relações sociais, culturais, históricas e políticas englobadas nas experiências migratórias, debilitando a apreensão de suas singularidades. (THEODORO, 2017) Em contrapartida, a partir de minhas incursões exploratórias em campo, foi possível verificar o surgimento de espaços de visibilidade de imigrantes LGBTIQ+ na cidade de São Paulo (como o Sarau Troca \& Ação, a roda de conversa sobre refugiadas/os LGBTQIA+ no SSEX BBOX de 2017 e os Encontros de Mulheres Imigrantes Lésbicas e Bissexuais de SP), bastante fundamentados na articulação entre movimentos sociais e TICs. (THEODORO; COGO, 2018)

Em meio a esses intrincados paradoxos da (in)visibilidade, poucas são as certezas e muitos os desafios. O que de fato podemos constatar são os tensionamentos entre visibilizar-se ou não, como se visibilizar minimizando riscos de uma precarização ainda mais grave da existência e quando e em que lugares promover essa visibilidade da diferença.

\section{Considerações finais}

Como procurei argumentar, no regime capitalista contemporâneo (ou farmacopornográfico), comunicação, práticas de consumo e a concretude simbólica das imagens estão intimamente relacionadas, e sua interface se condiciona à gestão biomidiática da subjetividade, por meio do 
controle molecular e da produção de conexões audiovisuais. (PRECIADO, 2008) Não podemos, portanto, compreender o espírito de nosso tempo sem considerar as implicações dessa tríade (ROCHA, 2017), que são centrais às políticas de visibilidade.

Acredito que seja válido, nesse sentido, reportar que, nas práticas de consumo que perpassam a produção-circulação-consumo de visualidades e visibilidades, está contida a imprevisibilidade de sentidos, principalmente no tocante ao polo da recepção, o que abre espaço a significações múltiplas, de onde podem emergir experiências de transgressão. Do plano das (re)significações imaginárias e negociações simbólicas do consumo, irrompe sua força ambivalente e disruptiva, pois "engloba vinculações não programáveis e suscetíveis a erro entre sujeitos de carne e osso e seres provenientes de outras familiaridades e procedências, inclusive as de ordem virtual, digital e invisível”. (ROCHA, 2017, p. 6)

Isso é importante para entender o quanto as visualidades $\mathrm{e}$ as visibilidades (principalmente da diferença) têm papel fundamental no processo de transformação social. Wesling (2008) aponta, por exemplo, que o incremento da visibilidade de sujeitos LGBTIQ+ na circulação midiática globalizada fomenta o reconhecimento de diferenças e mobilizações para que elas não sejam somente "toleradas", mas, sim, aceitas como parte integrante da condição humana. Assim, seus efeitos são psíquicos, materiais e sociais, abarcando uma potencialidade global por meio das TICs. Obviamente não devemos deixar de problematizar as formas pelas quais essas visibilidades são produzidas, veiculadas e consumidas, pois, conforme discutido, nem toda visibilidade é em si mesma positiva e sempre há o risco de naturalizar ou espetacularizar o imagético, o que leva a uma camuflagem dos jogos de poder e dos mecanismos de controle que o perpassam. (ROCHA, 2009)

Em uma conjuntura cada vez mais midiatizada e mediada pelas TICs, respondendo ao mesmo tempo às escusas leis do capital, está posta a necessidade de fundamentar uma epistemologia das visualidades, refletindo sobre a configuração não apenas das formas de sua produção-circulação-consumo, mas igualmente a respeito da dimensão do sujeito nelas contida. No caso da migração de sujeitos LGBTIQ+, torna-se primordial a problematização da construção dos regimes de significação enredados em suas (in)visibilidade sociocomunicacionais, pois é a partir deles que podemos pensar no fomento e na gestão de reais políticas cidadãs de visibilidade. 


\section{Referências}

ANDRADE, V. L. Imigração e sexualidade: solicitantes de refúgio, refugiados e refugiadas por motivos de orientação sexual na cidade de São Paulo. 2017. Dissertação (Mestrado em Antropologia Social) - Universidade Federal de Santa Catarina, Florianópolis, 2017.

BAITELLO, N. A serpente, a maçã e o holograma. São Paulo: Paulus, 2010.

COGO, D.; PÁSSARO, M. A "foto roubada": mídias, visibilidade e cidadania da imigração haitiana no Brasil. E-compós, Brasília, v. 20, n. 1, p. 1-23, 2017.

CRARY, J. Técnicas do observador: visão e modernidade no século XIX. Rio de Janeiro: Contraponto, 2012.

GARCÍA CANCLINI, N. Consumidores e cidadãos: conflitos multiculturais na globalização. Rio de Janeiro: Editora UFRJ, 1999.

HARVEY, D. Condição pós-moderna. São Paulo: Loyola, 1992.

HARVEY, D. O enigma do capital. São Paulo: Boitempo, 2011.

HIRATA, H. Gênero, classe e raça: interseccionalidade e consubstancialidade das relações sociais. Tempo Social, São Paulo, v. 26, n. 1, p. 61-73, 2014.

KRZESLO, E. Migrations et parcours d'exil: les femmes s'imposent. REMHU: Revista Interdisciplinar da Mobilidade Humana, Brasília, ano 15, n. 29, p. 121-137, 2007.

MACHADO, A. Máquina e imaginário. São Paulo: Edusp, 2001.

MOGROVEJO, N. Disidencia sexual y ciudadanía en la era del consumo neoliberal. Ciudad de México: Universidad Autónoma de la Ciudad de México, 2015.

NASCIMENTO, D. B. Refúgio LGBTI: panorama nacional e internacional. Porto Alegre: Editora Fi, 2018.

ORGANIZAÇÃO DAS NAÇÕES UNIDAS. Convenção Relativa ao Estatuto dos Refugiados (1951). Paris: ONU, 1951. Disponível em: http://bit.ly/3d0w7KG. Acesso em: 10 out. 2016.

PRECIADO, P. B. Testo junkie: sexe, drogue et biopolitique. Paris: Éditions Grasset \& Fasquelle, 2008.

ROCHA, R. M. Comunicação e consumo: por uma leitura política dos modos de consumir. In: BACCEGA, M. A. Comunicação e culturas do consumo. São Paulo: Atlas, 2008.

ROCHA, R. M. É a partir de imagens que falamos de consumo: reflexões sobre fluxos visuais e comunicação midiática. In: CASTRO, G. G. S.; BACCEGA, M. A. (org.). Comunicação e consumo nas culturas locais e global. São Paulo: ESPM, 2009. p. 268-293.

ROCHA, R. M. Esta noite encarnarei no teu objeto: a (des)possessão como mística e lógica capitalista. In: ENCONTRO ANUAL DA COMPÓS, 26., 2017, São Paulo. Anais [...]. São Paulo: Faculdade Casper Líbero, 2017.

THEODORO, H. G. S. "Meu país em mim": discursos sobre imigração por orientação sexual na mídia brasileira. Comunicologia: Revista de Comunicação da Universidade Católica de Brasília, Brasília, v. 10, n. 2, p. 164-181, 2017.

THEODORO, H. G. S.; COGO, D. Da diáspora queer: entre (in)visibilidades sociocomunicacionais e o exercício de cidadania. In: ENCONTRO ANUAL DA COMPÓS, 27., 2018, Belo Horizonte. Anais [...]. Belo Horizonte: Pontifícia Universidade Católica de Minas Gerais, 2018. [21] p. Disponível em: http://bit.ly/3aY2yri. Acesso em: 10 jun. 2018.

WESLING, M. Why queer diaspora? Feminist Review, Thousand Oaks, v. 90, n. 1, p. 30-47, 2008. 